\title{
Simulation of a Stably Stratified Atmospheric Boundary Layer Using One-Dimensional Turbulence
}

\author{
Alan R. Kerstein • Scott Wunsch
}

Published online: 10 June 2008

(C) Springer Science+Business Media B.V. 2008

Erratum to: Boundary-Layer Meteorology (2006) 118:325-356 DOI 10.1007/s10546-005-9004-x

In Eqs. 14 and 16, $\frac{27}{2} g D_{\theta}$ is replaced by $4 g D_{\theta} / T_{o}$.

The online version of the original article can be found under doi:10.1007/s10546-005-9004-x.

A. R. Kerstein $(\bowtie) \cdot$ S. Wunsch

Combustion Research Facility, Sandia National Laboratories, Livermore, CA 94551-0969, USA

e-mail: arkerst@sandia.gov 